\title{
Editorial: Action effects in perception and action
}

\section{Roland Pfister*, Markus Janczyk and Wilfried Kunde}

Department of Psychology III, Julius Maximilians University of Würzburg, Würzburg, Germany

*Correspondence: roland.pfister@psychologie.uni-wuerzburg.de

\section{Edited by:}

Bernhard Hommel, Leiden University, Netherlands

Good scientific theories should be simple, valid, and stimulating. It seems that ideomotor theory, which has been the core theme behind the research topic on "Action Effects in Perception and Action," has done a fairly good job in terms of these three criteria. First, it is rather simple: goal-directed actions are assumed to be selected and addressed by anticipating their sensory consequences; crucially, learned bidirectional associations between sensory representations and motor commands ensure that these anticipations eventually result in overt behavior. Secondly, numerous observations comply with its basic predictions, derived from philosophical analyses of the nineteenth century (cf. Stock and Stock, 2004; Pfister and Janczyk, 2012). Accordingly, the validity of ideomotor theory has been documented by extensive empirical research over the last decades (e.g., Elsner and Hommel, 2001; Hommel et al., 2001; Kunde, 2001; see also Shin et al., 2010).

Thirdly, ideomotor theory (still) seems to stimulate contemporary research. Otherwise the impressive range of topics that have come together in the present research topic can hardly be explained. These topics range from investigations of how attention and perception are modulated by intentions and expectations (Kemper et al., 2012; Wykowska and Schubö, 2012), to applied settings such as aging and tool-use (Sutter et al., 2012), taskswitching (Lukas et al., 2013), to social influences on action coding (Colzato et al., 2012; Nishimura and Michimata, 2013) and a developmental perspective on action effects in object manipulation (Knudsen et al., 2012). These new perspectives are backed up by studies on two prevailing questions in ideomotor research: The formation of action-effect associations (Herwig and Waszak, 2012; Janczyk et al., 2012; Ruge et al., 2012)_including a first step toward addressing individual differences in ideomotor learning (Muhle-Karbe and Krebs, 2012) — and the role of such associations for action control (Gaschler and Nattkemper, 2012; Walter and Rieger, 2012; Ziessler et al., 2012).

Furthermore, three notable articles explore theoretical refinements of ideomotor theory by addressing the virtue of visuomotor priming for ideomotor research (Thomaschke, 2012), hierarchical coding of action-effect relations (Ondobaka and

\section{REFERENCES ${ }^{1}$}

Baess, P., Horváth, J., Jacobsen, T., and Schröger, E. (2011). Selective suppression of self-initiated sounds in an auditory stream: an ERP study. Psychophysiology 48, $1276-1283$.

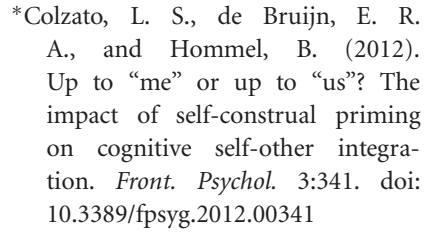
A., and Hommel, B. (2012). Up to "me" or up to "us"? The impact of self-construal priming on cognitive self-other integration. Front. Psychol. 3:341. doi: 10.3389/fpsyg.2012.00341

Bekkering, 2012) and computational constraints for ideomotor theory (Herbort and Butz, 2012).

In the light of these and other recent empirical and theoretical advances (cf. Shin et al., 2010), it seems as if twenty-first century ideomotor theory accounted for almost all areas of cognitive psychology. On careful consideration, however, it also seems as if a particular area is still underrepresented in the ideomotor community, and this area is the concept of working memory. Whereas there are a several short hints to "memory traces" or "long-term memory" throughout the articles of the research topic, the concept of working memory is mentioned only a single time (Thomaschke, 2012, p. 4). Arguably, however, anticipated action effect must be represented somewhere in the cognitive architecture-and working memory appears a likely place for these representations. In our view, this state of affairs is indicative of the current theoretical state and calls for a better exchange between the respective scientific communities.

Similarly, while the sketched developments and directions are admirable on their own, they also pose a new challenge for scholars of action and perception. This challenge relates to an explicit treatment of the relations-commonalities and differences-of the ideomotor approach to other general frameworks for action and perception. For instance, the neuroscientific approaches of predictive coding (Rao and Ballard, 1998), the Bayesian brain (Knill and Pouget, 2004), and the free-energy principle (Friston, 2010) seem to share many features with the principles of effectbased action control even though the different accounts are rarely discussed in the same place (and are nourished by distinct scientific communities). In the same vein, relations to accounts for the perception of self-generated action effects (Haggard et al., 2002; Baess et al., 2011; Moore and Obhi, 2012) need a more explicit treatment, and so do the relations to mathematical models of human motor control (Wolpert and Ghahramani, 2000).

In the meantime, we would like to thank all authors who joined the enterprise of this research topic, and all reviewers who commented on the presented papers. It was a pleasant enterprise from beginning to end, i.e., from sending out the first invitations up to the final, joint action effect which is the research topic itself.

Elsner, B., and Hommel, B. (2001). Effect anticipation and action control. J. Exp. Psychol. Hum. Percept. Perform. 27, 229-240.

Friston, K. (2010). The free-energy principle: a unified brain theory? Nat. Rev. Neurosci. 11, 127-138.
*Gaschler, R., and Nattkemper, D. (2012). Instructed task demands and utilization of action effect anticipation. Front. Psychol. 3:578. doi: 10.3389/fpsyg.2012.00578

Haggard, P., Clark, S., and Kalogeras, J. (2002). Voluntary action and

\footnotetext{
${ }^{1}$ Articles that are part of the research topic are marked with asterisks $\left({ }^{*}\right)$.
} 
conscious awareness. Nat. Neurosci. 5, 382-385.

*Herbort, O., and Butz, M. V. (2012). Too good to be true? Ideomotor theory from a computational perspective. Front. Psychol. 3:494. doi: 10.3389/fpsyg.2012.00494

*Herwig, A., and Waszak, F., (2012). Action-effect bindings and ideomotor learning in intention- and stimulus-based actions. Front. Psychol. 3:444. doi: 10.3389/fpsyg.2012.00444

Hommel, B., Müsseler, J., Aschersleben, G., and Prinz, W. (2001). The theory of event coding: a framework for perception and action. Behav. Brain Sci. 24, 849-878.

*Janczyk, M., Heinemann, A., and Pfister, R. (2012). Instant attraction: immediate action-effect bindings occur for both, stimulusand goal-driven actions. Front. Psychol. 3:446. doi: 10.3389/fpsyg. 2012.00446

*Kemper, M., Umbach, V. J., Schwager, S., Gaschler, R., Frensch, P. A., and Stürmer, B. (2012). What I say is what I get: stronger effects of self-generated vs. cue-induced expectations in event-related potentials. Front. Psychol. 3:562. doi: 10.3389/fpsyg.2012.00562

Knill, D. C., and Pouget, A. (2004). The Bayesian brain: the role of uncertainty in neural coding and computation. Trends Neurosci. 27, 712-719.
*Knudsen, B., Henning, A., Wunsch, K., Weigelt, M., and Aschersleben, G. (2012). The end-state comfort effect in 3- to 8-year-old children in two object manipulation tasks. Front. Psychol. 3:445. doi: 10.3389/fpsyg.2012.00445

Kunde, W. (2001). Response-effect compatibility in manual choice reaction tasks. J. Exp. Psychol. Hum. Percept. Perform. 27, 387-394.

*Lukas, S., Philipp, A. M., and Koch, I. (2013). The influence of action effects in task-switching. Front. Psychol. 3:595. doi: 10.3389/fpsyg.2012.00595

Moore, J. W., and Obhi, S. S. (2012). Intentional binding and the sense of agency: a review. Conscious. Cogn. 21, 546-561.

*Muhle-Karbe, P. S., and Krebs, R. M. (2012). On the influence of reward on action-effect binding. Front. Psychol. 3:450. doi: 10.3389/fpsyg.2012.00450

*Nishimura, A., and Michimata, C. (2013). Pointing hand stimuli induce spatial compatibility effects and effector priming. Front. Psychol. 4:219. doi: 10.3389/fpsyg.2013.00219

*Ondobaka, S., and Bekkering, $\mathrm{H}$. (2012). Hierarchy of idea-guided action and perception-guided movement. Front. Psychol. 3:579. doi: 10.3389/fpsyg.2012.00579

Pfister, R., and Janczyk, M. (2012). Harleß' apparatus of will: 150 years later. Psychol. Res. 76, 561-565.

Rao, R. P., and Ballard, D. H. (1998). Predictive coding in the visual cortex: a functional interpretation of some extra-classical receptive field effects. Nat. Neurosci. 2, 79-87.

*Ruge, H., Krebs, R. M., and Wolfensteller, U. (2012). Early markers of ongoing action-effect learning. Front. Psychol. 3:522. doi: 10.3389/fpsyg.2012.00522

Shin, Y. K., Proctor, R. W., and Capaldi, E. J. (2010). A review of contemporary ideomotor theory. Psychol. Bull. 136, 943-974.

Stock, A., and Stock, C. (2004). A short history of ideo-motor action. Psychol. Res. 68, 176-188.

*Sutter, C., Ladwig, S., Oehl, M., and Müsseler, J. (2012). Age effects on controlling tools with sensorimotor transformations. Front. Psychol. 3:573. doi: 10.3389/fpsyg.2012.00573

*Thomaschke, R. (2012). Investigating ideomotor cognition with motorvisual priming paradigms: key findings, methodological challenges, and future directions. Front. Psychol. 3:519. doi: 10.3389/fpsyg.2012.00519

*Walter, A. M., and Rieger, M. (2012). Similar mechanisms of movement control in target- and effectdirected actions toward spatial goals? Front. Psychol. 3:539. doi: 10.3389/fpsyg.2012.00539
Wolpert, D. M., and Ghahramani, Z. (2000). Computational principles of movement neuroscience. Nat. Neurosci. 3, 1212-1217.

*Wykowska, A., and Schubö, A. (2012). Action intentions modulate allocation of visual attention: electrophysiological evidence. Front. Psychol. 3:379. doi: 10.3389/fpsyg.2012.00379

*Ziessler, M., Nattkemper, D., and Vogt, S. (2012). The activation of effect codes in response preparation: new evidence from an in direct priming paradigm. Front. Psychol. 3:585. doi: 10.3389/fpsyg.2012.00585

Received: 10 April 2013; accepted: 11 April 2013; published online: 03 May 2013.

Citation: Pfister R, Janczyk $M$ and Kunde $W$ (2013) Editorial: Action effects in perception and action. Front. Psychol. 4:223. doi: 10.3389/fpsyg.2013.00223

This article was submitted to Frontiers in Cognition, a specialty of Frontiers in Psychology.

Copyright (C) 2013 Pfister, Janczyk and Kunde. This is an open-access article distributed under the terms of the Creative Commons Attribution License, which permits use, distribution and reproduction in other forums, provided the original authors and source are credited and subject to any copyright notices concerning any third-party graphics etc. 